\title{
Interspecific variation in life history traits of Elasmostethus (Hemiptera: Acanthosomatidae)- ERRATUM
}

\section{Shin-ichi Kudo, Aki Yamamoto, Tadao Ichita, Haruki Tatsuta}

https://doi.org/10.4039/tce.2018.56, published online by Cambridge University Press, 20 November 2018.

Shin-ichi Kudo's name was misspelled in the original publication of this article (Kudo et al. 2018). The original has since been updated.

The publisher apologies for this error.

\section{Reference}

Kudo, S., Yamamoto, A., Ichita, T., and Tatsuta, H. 2018. Interspecific variation in life history traits of Elasmostethus (Hemiptera: Acanthosomatidae). The Canadian Entomologist, 151. https://doi.org/10.4039/tce.2018.56 